\title{
PROMOVENDO A EDUCAÇÃO AMBIENTAL E SUSTENTABILIDADE ATRAVÉS DA PRÁTICA DA AGRICULTURA DE BASE ECOLÓGICA
}

\author{
Sílvia Naiara de Souza Borba ${ }^{1}$ \\ Daiane Loreto de Vargas \\ José Geraldo Wizniewsky
}

\section{Resumo}

A educação ambiental se dá em diversos âmbitos, sejam eles teóricos ou práticos, e tem como preconizador a conscientização da população com relação ao meio ambiente. A iniciativa de implantação de hortas ecológicas suspensas no meio escolar é uma alternativa para estar gerando uma responsabilidade entre os alunos que a mantém. O objetivo da implantação da horta é de, além de estar incentivando práticas de educação ambiental através do cultivo de hortaliças de forma orgânica, estimular os alunos a reutilizarem materiais. Para a realização da horta suspensa foram utilizadas garrafas pet, fios de nilon, pregos, folhas de ofício, lápis para colorir, tesoura e fita adesiva. As atividades foram realizadas com crianças do primeiro ao quarto ano da Escola Estadual de Ensino Fundamental Dr. Honorato de Souza Santos, Cachoeira do Sul/RS. Conclui-se, que a horta ecológica suspensa servirá de base para perspectivas sustentáveis nas diversas fases de vida de um indivíduo, promovendo segurança alimentar sem impactar a natureza.

Palavras-chave: horta suspensa, educação ambiental, reciclagem.

\section{INTRODUÇÃO E CONTEXTUALIZAÇÃO DO TEMA}

Dentro do âmbito escolar, algumas atividades práticas são passíveis de estarem sendo implantadas, atividades estas, que estarão complementando os conteúdos programáticos das disciplinas, sendo consideradas propostas interdisciplinares. Estas novas visões educacionais formam cidadãos com diferenciais imprescindíveis no mundo globalizado em que nos inserimos.

A horta suspensa ocorre como uma nova proposta educativa e tem por objetivo, auxiliar na formação sociocultural de estudantes, fazendo com que os mesmos além de aprenderem a reciclar, no caso de garrafa pet, busquem no plantio de hortaliças, suporte para estarem garantindo segurança alimentar e nutricional de suas famílias e futuras gerações. Quanto à segurança alimentar e nutricional, considera-se que a prática da horta suspensa pelos alunos, propicie aos mesmos a possibilidade de produzirem alimentos de forma sustentável e ecológica.

Pode-se elencar algumas vantagens para estar promovendo esta atividade extracurricular: a produção de base ecológica sem a utilização de agrotóxicos e seus riscos a saúde e meio ambiente; o estímulo do trabalho em equipe; a incitação a mudança de hábitos alimentares e ainda a prática da reciclagem de materiais 
III SEMINÁRII ECOLOGIA

PDLÍTICA

descartáveis. Segundo Carvalho (2004), esta forma de Educação Ambiental (EA) "contribui para uma mudança de valores e atitudes, contribuindo para a formação de um sujeito ecológico".

A EA requer conhecimento de caráter social como: valores culturais, morais, justiça, saúde, a noção de cidadania, entre outros aspectos que conformam a totalidade social (CRIBB, 2010).

O objetivo da implantação de uma horta suspensa é de, além de estar incentivando práticas de Educação Ambiental através do cultivo de hortaliças de forma orgânica, estimular os alunos a reaproveitarem materiais, como garrafas pet. Além disso, a integração dos alunos resulta em momentos de socialização, troca de experiências e interações entre todos os envolvidos. Esta prática também desperta aos educandos para a prática da agricultura em espaços restritos de próprio meio urbano.

O presente trabalho tem como principal objetivo, detalhar uma das atividades realizadas pelo eixo de agroecologia, vinculado ao subprojeto Arquitetos do Saber, este compondo o projeto Capes Novos Talentos. Esta atividade diz respeito à implantação de uma horta suspensa, com a orientação da agroecologia, na Escola Estadual de Educação de Ensino Fundamental Dr ${ }^{\circ}$. Honorato de Souza Santos, localizada na cidade de Cachoeira do Sul, em uma região peri-urbana da cidade.

\subsection{A reciclagem como prática de educação ambiental e sustentabilidade}

A EA exerce um importante papel na conscientização para práticas que minimizem os impactos ambientais negativos. De acordo com a Lei 9.795/99 de 27 de abril de 1999, art. $1^{\text {o. }}$

Entendem-se por educação ambiental os processos por meio dos quais o indivíduo e a coletividade constroem valores sociais, conhecimentos, habilidades, atitudes e competências voltadas para a conservação do meio ambiente, bem de uso comum do povo, essencial à sadia qualidade de vida e sua sustentabilidade (DIÁRIO OFICIAL DA UNIÃO ON-LINE, 1999, p.1).

Locais considerados coletivos, onde os conhecimentos são compartilhados tornam-se importantes ferramentas na divulgação de estratégias para combater ou minimizar problemáticas identificadas no contexto mundial. Um ambiente que pode 
proporcionar discussões e entendimentos sobre estas abordagens, diz respeito ao âmbito escolar, pois além de reunir diversas culturas, é o momento em que conhecimentos são propagados com o fim de despertar no educando, o exercício da cidadania, onde, sem sombra de dúvidas o direito a alimentação adequada e saudável deve ser incluída.

Segundo a UNESCO (2005) "Educação Ambiental é campo de conhecimento bem estabelecido que enfatiza a relação dos homens com o ambiente natural, as formas de conservá-lo, preservá-lo e de administrar seus recursos adequadamente". Assim, a EA interliga o homem a natureza e estabelece entre eles uma relação de cumplicidade e de juízo quanto à processos biológicos e físicos que ocorrem em função de algumas atitudes da ação humana, tornando a escola um ator relevante para esta conexão.

Para contribuir e dar continuidade ao assunto, Pontalti (2005), refere-se à escola como sendo a representação do espaço onde o aluno dará sequência ao seu processo de socialização, iniciado em casa, com seus familiares. Diante da importância deste espaço, algumas medidas podem ser adotadas para contribuírem na educação continuada e formação do caráter dos educandos e suas futuras intervenções nas propostas de melhoria em diversos âmbitos sociais.

Para Tozoni-Reis (2008), refletir sobre a Educação Ambiental na escola exige, em primeiro lugar, que pensemos sobre a relação entre educação, escola e sociedade. E é esta relação que oportuniza a disseminação de ideias e discussões para posteriores tomadas de decisões que influenciarão no direcionamento de, por exemplo, as políticas públicas.

Dentro do ambiente escolar, várias são as alternativas para estarem debatendo a questão ambiental, entre elas atividades práticas ou teóricas relacionado a dado tema. A reutilização de materiais é uma das formas utilizadas para elucidar esta afirmativa, já que na maioria das vezes, alguns destes materiais trazem consigo poluição em nível de solo e também de saúde pública. Podemos citar o caso das garrafas pet, como sendo um exemplo de material que comumente são jogadas nos rios e riachos, praças públicas entre outros locais, consistindo inclusive em abrigo para algumas espécies de roedores. Se reutilizadas para outros propósitos, as garrafas pet se apresentam como importantes aliadas da conservação de um meio ambiente limpo.

Tão importante como debater problemas é discutir soluções, e para isto, o desenvolvimento de oficinas dentro de escolas, visando a educação para a 
sustentabilidade, se torna uma proposta viável e construtora na vida do indivíduo que participa de tais ações. O subprojeto Arquitetos do Saber, da Universidade Federal de Santa Maria, foi desenvolvido a partir de uma proposta magna da CAPES - Projeto Novos Talentos. O público deste subprojeto são os educandos da Escola Estadual de Ensino Fundamental Dr. Honorato de Souza Santos, localizada na localidade Passo d'areia, área peri-urbana do município de Cachoeira do Sul/RS.

Na escola Dr. Honorato de Souza Santos são trabalhados três eixos que se intitulam Agroecologia, Educação Ambiental e Cidadania, sendo a Oficina de Horta Suspensa, uma das práticas do Eixo da Agroecologia.

\subsection{Oficina de horta suspensa e sua contribuição social}

Além de temas abordando práticas com a orientação da agroecologia, o eixo vem a contribuir com assuntos relacionados ao meio ambiente como um todo, desde a questão de educação ambiental até a questão de segurança alimentar.

Seguindo na lógica de produção sustentável, a horta que produz alimentos sem utilização de agrotóxicos vem a contribuir de forma benéfica ao meio ambiente, à alimentação e ao bem estar dos indivíduos. Todavia, uma horta que além dessas atribuições ainda contribui para a reutilização de materiais, considerados lixos, torna-se referência para colaborar com uma sociedade em busca da sustentabilidade.

A Oficina de horta suspensa aconteceu no mês de maio de dois mil e doze, e teve como propósito o incentivo à uma alimentação saudável, sem agrotóxicos ou outros químicos, além de enfatizar a reutilização de materiais e o incentivo a prática da agricultura urbana.

Neste dia, os alunos reuniram-se primeiramente na sala de aula, onde foi apresentado aos mesmos, um material visual o qual explicitava a poluição dos rios, praias e espaços urbanos com garrafas pet, principalmente. Desta forma enfatizou-se a questão da reciclagem e reutilização desses materiais que são potenciais riscos ao meio ambiente caso seu destino não seja adequado, servindo de meio para o desenvolvimento de potenciais vetores de doenças transmitidas aos seres humanos. Num segundo momento, houve a interação das crianças com os utensílios da Oficina como garrafas pet, fios de nilon, pregos, folhas de ofício, lápis para colorir, tesoura e fita adesiva 


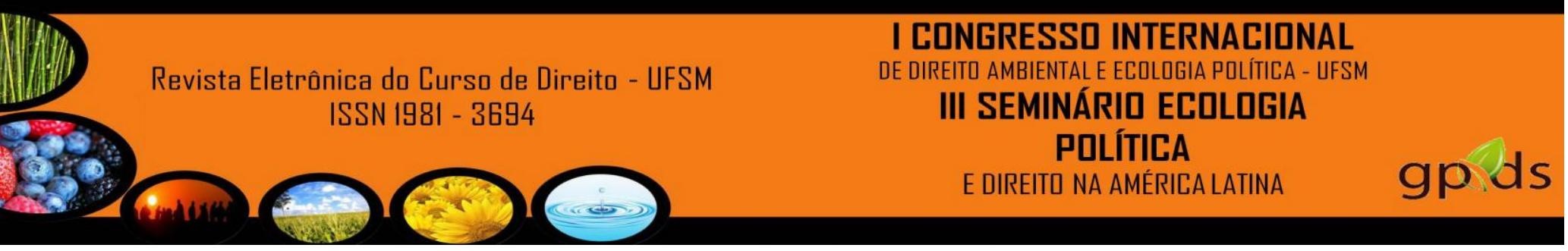

transparente. Cada aluno ficou responsável por um pet, colorindo um desenho de uma flor e sob esta seu nome. Um cartaz foi confeccionado pelos membros do Eixo Agroecologia, no qual, cada aluno tinha seu próprio calendário o qual servir-lhe-ia de controle para cada hortaliça. Nos calendários foram estabelecidos os dias letivos até o posterior encontro das crianças com o Eixo. Observa-se na figura 1. os pet com as hortaliças.

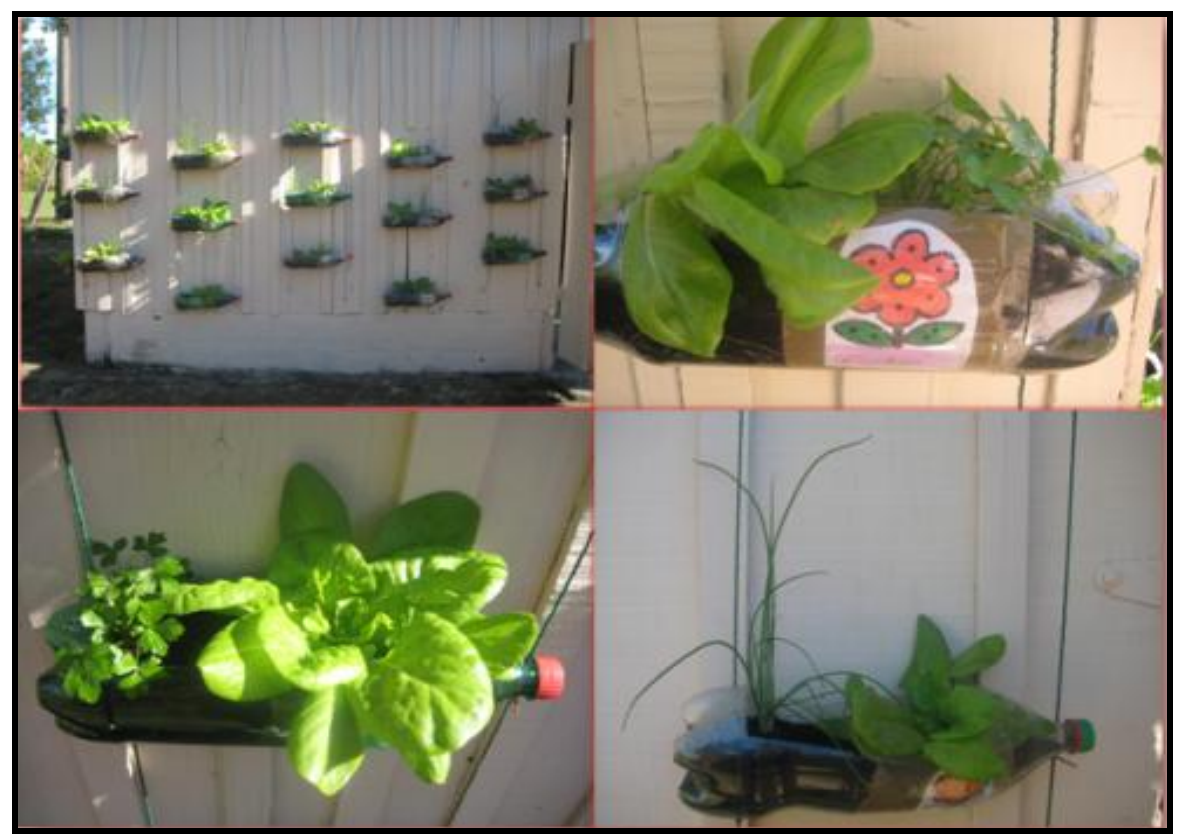

Figura 1. Horta suspensa com hortaliças plantadas pelos alunos da Escola Estadual de Ensino Fundamental Dr. Honorato de Souza Santos.

A educação básica é o caminho para assegurar a todos os brasileiros a formação comum indispensável para o exercício da cidadania e fornecer-lhes os meios para progredir no trabalho e em estudos posteriores (MEC, 2012). As oficinas realizadas com as crianças vão dando os aportes necessários para que, possam usar o bom senso quando estiverem à frente de uma questão que envolva o meio ambiente. O objetivo do Eixo é estar evidenciando a este público, alternativas para uma conduta mais coerente com os recursos naturais disponíveis, além de reforçar através de explanações o quanto eles são importantes nesta fase de transição, seja ela para qualquer campo que vise a sustentabilidade.

A Oficina de Horta Suspensa, além de abordar questões relacionadas ao meio ambiente, demonstrou aos educandos que a produção orgânica de hortaliças de aliada a 



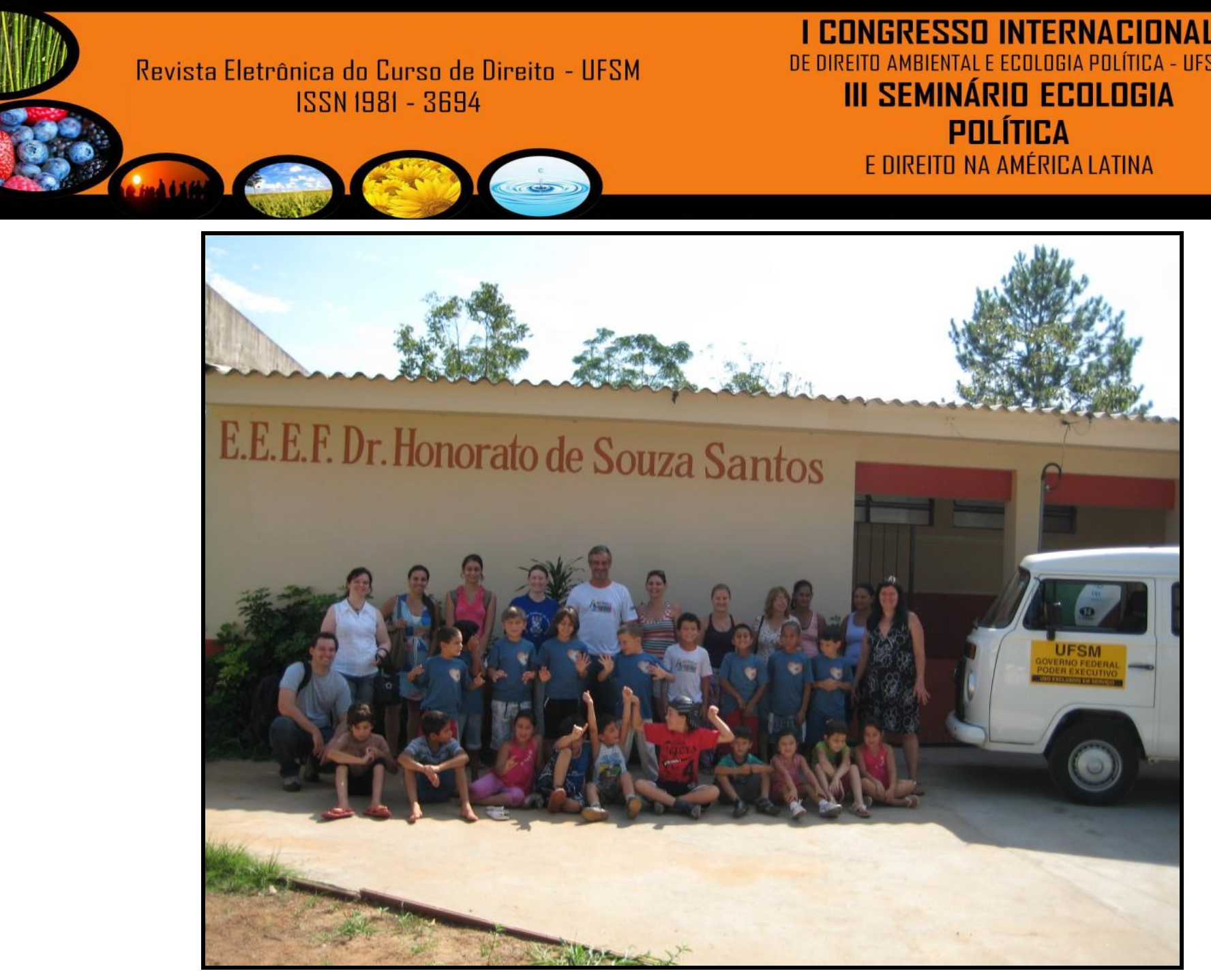

Fig. 2. Visita do subprojeto Arquitetos do Saber à E.E.E.F.Dr. Honorato de Souza Santos, Cachoeira do Sul/RS.

\section{CONSIDERAÇÕES FINAIS}

A cerca do trabalho exposto, é possível concluir que a Educação Ambiental envolve estratos como educação, escola e sociedade. Sendo assim, iniciativas que chegarem até a escola e se estas forem de forma educativa, poderão se propagar na sociedade, dependendo das estratégias utilizadas pelos interventores. Esta tática é eficiente para serem tratados assuntos considerados problemáticas mundiais, no caso a questão ambiental.

A Oficina de horta suspensa colaborou para os educandos entenderem a importância da produção de base ecológica, utilizando os princípios da Agroecologia, a qual é realizada livres de resíduos químicos, e para despertar um "olhar especial” à alguns materiais que são descartados a céu aberto por uma parcela da população, 


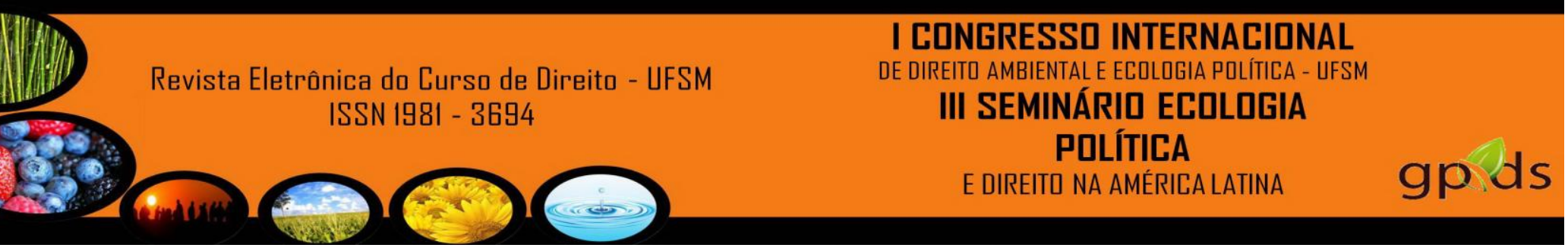

constituindo-se em lixo com um potencial poluente e com um reaproveitamento pode se transformar em um substrato para a produção sustentável de alimentos.

Ainda cabe ressaltar que a EA, envolve diversos fatores, entre eles os culturais e sociais. Portanto, práticas como a descrita, favorecem a socialização entre os alunos, fazendo-os ter atitudes condizentes com princípios de cidadania, agroecologia e educação ambiental.

\section{REFERÊNCIAS}

BRASIL. Lei n. 9.795, de 27 de abril de 1999. Dispõe sobre a Educação Ambiental, institui a Política Nacional de Educação Ambiental e dá outras providências. Brasília: Diário Oficial da União, Brasília, DF, 27 abr. 1999. Disponível em: < http://www.educadoresambientais.com.br/downloads/Lei\%209795.pdf. > Acesso em: 20 ago. 2012.

CARVALHO, Isabel Cristina de Moura. Educação Ambiental Crítica: nomes e endereçamentos da educação In: LAYRARGUES, P.P. (coord.). Identidades da educação ambiental brasileira. Ministério do Meio Ambiente. Diretoria de Educação Ambiental. Brasília, Ministério do Meio Ambiente, 2004.

CRIBB, S. L. S. P. Contribuições da educação ambiental e horta escolar na promoção de melhorias ao ensino, à saúde e ao ambiente. REMPEC - Ensino, Saúde e Ambiente, v.3, n.1, p. 42-60, 2010.

MALUF, R. S. e al. Contribuição ao tema de segurança alimentar no Brasil. Cadernos de Debate, Campinas, v. 4, 1996, p. 66-88. Disponível em: < http://www.pachamama.agr.br/biblioteca/MALUF001.pdf>. Acesso em 25 jun. 2012.

MINISTÉRIO DA EDUCAÇÃO. Secretaria da educação básica. Brasília/DF, 2012. Disponível

em: $<$ http://portal.mec.gov.br/index.php?option=com_content \& view=article\&id=293\&Itemi d=358>. Acesso em: 30 jul. 2012.

PONTALTI, Edna Sueli. Projeto de Educação Ambiental: Parque Cinturão Verde de Cianorte. APROMAC: Associação de proteção ao Meio Ambiente Cianorte. Disponível em: <http://www.apromac.org.br/ea005.htm>. Acesso em: 20 jul. 2012.

TOZONI-REIS, M. F.C. Educação Ambiental no Brasil. Salto para o futuro, ano XVIII, boletim $01, \quad$ mar. 2008 . Disponível em: <http://tvbrasil.org.br/fotos/salto/series/164816Educambiental-br.pdf>. Acesso em: 22 ago. 2012.

UNESCO. ORGANIZAÇÃO DAS NAÇÕES UNIDAS PARA A EDUCAÇÃO, CIÊNCIA E CULTURA. Década das Nações Unidas da Educação para um 


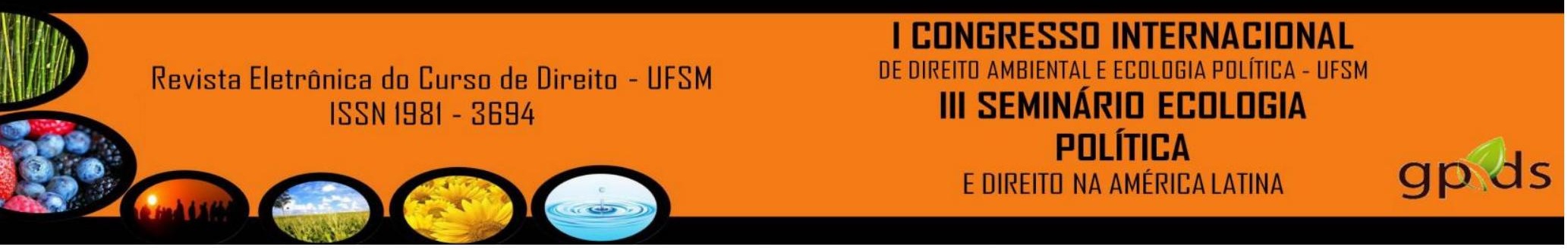

Desenvolvimento Sustentável, 2005-2014: documento final do esquema internacional de implementação, Brasília/DF, 2005. Disponível em: < http://unesdoc.unesco.org/images/0013/001399/139937por.pdf $>$. Acesso em: 23 jul. 2012. 